\title{
Lusioersily
}

\section{Production and Roles of Biosurfactants and Bioemulsifiers in Accessing Hydrophobic Substrates.}

Perfumo, A., Smyth, T., Marchant, R., \& Banat, I. (2010). Production and Roles of Biosurfactants and

Bioemulsifiers in Accessing Hydrophobic Substrates. In KN. Timmis (Ed.), Handbook of Hydrocarbon and Lipid Microbiology (Vol. 2, pp. 1501-1512). Springer. https://doi.org/10.1007/978-3-540-77587-4_103

Link to publication record in Ulster University Research Portal

\section{Published in:}

Handbook of Hydrocarbon and Lipid Microbiology

Publication Status:

Published (in print/issue): 01/01/2010

DOI:

10.1007/978-3-540-77587-4_103

\section{Document Version}

Publisher's PDF, also known as Version of record

\section{General rights}

Copyright for the publications made accessible via Ulster University's Research Portal is retained by the author(s) and / or other copyright owners and it is a condition of accessing these publications that users recognise and abide by the legal requirements associated with these rights.

\section{Take down policy}

The Research Portal is Ulster University's institutional repository that provides access to Ulster's research outputs. Every effort has been made to ensure that content in the Research Portal does not infringe any person's rights, or applicable UK laws. If you discover content in the Research Portal that you believe breaches copyright or violates any law, please contact pure-support@ulster.ac.uk. 


\section{Production and Roles of Biosurfactants and Bioemulsifiers in Accessing Hydrophobic Substrates}

A. Perfumo - T. J. P. Smyth - R. Marchant - I. M. Banat* School of Biomedical Sciences, University of Ulster, Coleraine, County Londonderry, Northern Ireland, UK *IM.Banat@ulster.ac.uk

1 Introduction

2 Distribution of Biosurfactant-Producing Microorganisms in the Environment

3 Rhamnolipid Biosurfactants in Pseudomonas aeruginosa

4 Surface-Active Lipids of Rhodococcus and Mycolate-Containing Microorganisms

5 Glycolipids of Alcanivorax in Marine Environments 1507

6 The Lipopeptide Biosurfactants 1508

7 High Molecular Mass Bioemulsifiers 1509

8 Research Needs and Conclusions 1510 
Abstract: Biosurfactants are one of the numerous adaptations of microorganisms metabolizing hydrocarbons and broadly represent a physiological response to specific requirements encountered by the cells depending on their environment. Some bacteria have developed the "pseudosolubilization" strategy to gain access to poorly soluble substrates and therefore produce highly dynamic low-molecular mass biosurfactants characterized by the capability to self-assembly in micelles, hemi-micelles or aggregates. Other bacteria interact with hydrocarbons directly by means of wall-bound biosurfactants that confer on the cell surface the appropriate hydrophobicity. High molecular mass bioemulsifiers in general adsorb tightly and cover the hydrocarbons thus dramatically increasing their apparent solubility.

Although a variety of mechanisms and specializations distinguish biosurfactants, they all share a few essential traits. They are part of the process of interaction of microbial cells with surfaces as well as substrates. In addition to working on hydrocarbon solubilization they also act at the level of the cellular outer membrane allowing temporary and reversible modifications that control substrate access by the cells. As a consequence, a "substrate effect" can often be observed. Although the biosynthetic mechanisms for most remain unclear, substrates seem able to influence structural variations that make the biosurfactants particularly active towards the same substrate. Finally, many biosurfactants and their producing strains stimulate the growth of differently specialized bacteria which suggests that these molecules play a vital role in the interaction between the oil-degrading microbial communities and their environment.

\section{1} Introduction

A large number of hydrophobic compounds continuously enter the environment, either as natural products originating from animals, plants and microorganisms such as steroids, terpenes and waxes or pollutants produced by anthropogenic activities such as hydrocarbons, petroleum and its derivatives. These substrates are degraded by microorganisms which have the ability to colonize almost all ecological niches as a result of their metabolic versatility and adaptability to different carbon sources. Many of these substances are characterized by low aqueous solubility and high solid-water distribution ratios (Johnsen et al., 2005). This limits their interaction with microbial cells which principally use molecules that are dissolved in the water phase. Substrate bioavailability is therefore an important factor, affected by complex processes in which many factors, not only physical and chemical substrate characteristics, play a significant role. They include for example the environment or matrix (e.g., water, soil, sediment, organic matter, etc.), the kinetic parameters (e.g., diffusion and flow rate, mass transfer, spatial separation between cells and substrate, etc.) as well as the intrinsic physiological properties of the cells (Johnsen et al., 2005).

Microorganisms have adopted different strategies to enhance the bioavailability and gain access to hydrophobic compounds, such as hydrocarbons, including (1) biosurfactantmediated solubilization, (2) direct access of oil drops and (3) biofilm-mediated access (Hommel, 1990). The production of biosurfactants and bioemulsifiers is generally involved, although to different degrees, in all the above strategies.

Biosurfactant structural uniqueness resides in the coexistence of a hydrophilic (a sugar or peptide) and a hydrophobic (fatty acid chain) domain in the same molecule, which allows them to occupy the interface of mixed phase systems (e.g., oil/water, air/water, oil/solid/water) and consequently to alter the forces governing the equilibrium conditions. This is the 
prerequisite for a broad range of surface activities to take place including emulsification, dispersion, dissolution, solubilization, wetting and foaming (Banat et al., 2000; Desai and Banat, 1997 (See $\odot$ Chapter 27 and $>$ 28, Vol. 5, Part 2)).

Moreover biosurfactants seem to confer an essential evolutionary advantage allowing microorganisms to grow under specific conditions as evidenced by their wide distribution across the eubacterial and archeal domains (Bodour et al., 2003). This chapter will discuss how biosurfactants facilitate the hydrocarbon utilization in some representative hydrocarbon degrading-bacteria with emphasis on the diversity of these molecules (e.g., structural variants, physical and chemical properties and biosynthesis conditions) as specific response to needs, life-style and environmental niche of different microorganisms.

\section{Distribution of Biosurfactant-Producing Microorganisms in the Environment}

Biosurfactant-producing microorganisms are ubiquitous, inhabiting both water (sea, fresh water, groundwater) and land (soil, sediment, sludge) as well as extreme environments (e.g., oil reservoirs), and thriving at a wide range of temperatures, $\mathrm{pH}$ values and salinity. They can also be isolated from undisturbed environments where they have physiological roles not involving the solubilization of hydrophobic pollutants e.g., antimicrobial activity, biofilm formation or processes of motility and colonization of surfaces (Van Hamme et al., 2006). However, it is among the hydrocarbon-degrading microbial communities that the capability to produce biosurfactants is most widespread. Hydrocarbon-degrading bacterial populations are generally dominated by a few main bacterial genera such as Pseudomonas, Bacillus, Sphingomonas and Actinobacteria in soils and sediments, and Pseudoalteromonas, Halomonas, Alcanivorax and Acinetobacter in marine ecosystems. It is not surprising therefore that a lot of biosurfactant or bioemulsifier-producers belong to these same genera. An estimate of the frequency of biosurfactant-producing strains within a microbial population cannot be easily determined as it depends on the experimental procedures used. It has been reported that $2-3 \%$ of screened populations in uncontaminated soils are biosurfactant-producing microorganisms which increases to $25 \%$ in polluted soils (Bodour et al., 2003). On the other hand, enrichment culture techniques specific for hydrocarbon-degrading bacteria may lead to a much higher detection of biosurfactant-producers with estimates up to $80 \%$ (Rahman et al., 2002).

However, the small number of investigations and a still naïve study methodology limit our current understanding of biosurfactant-producing microorganisms so that occurrence and distribution in the environment are likely underestimated.

\section{Rhamnolipid Biosurfactants in Pseudomonas aeruginosa}

Rhamnolipids are biosurfactants exclusive to Pseudomonas aeruginosa although they have been recently reported to be produced by the phylogenetically related species Pseudomonas chlororaphis (Gunther et al., 2005). They are in the glycolipid family and their distinctive trait is the presence of one or two rhamnose sugar units linked to one or two units of $\beta$-hydroxy-fatty acids with typical chain length ranging from $\mathrm{C}_{8}$ to $\mathrm{C}_{12}$. Rhamnolipids are usually produced as a mixture of numerous congeners with the di-rhamnolipid- $\mathrm{C}_{10}-\mathrm{C}_{10}$ being the predominant form ( Fig. 1a,b). They are secondary metabolites whose production occurs constitutively at 

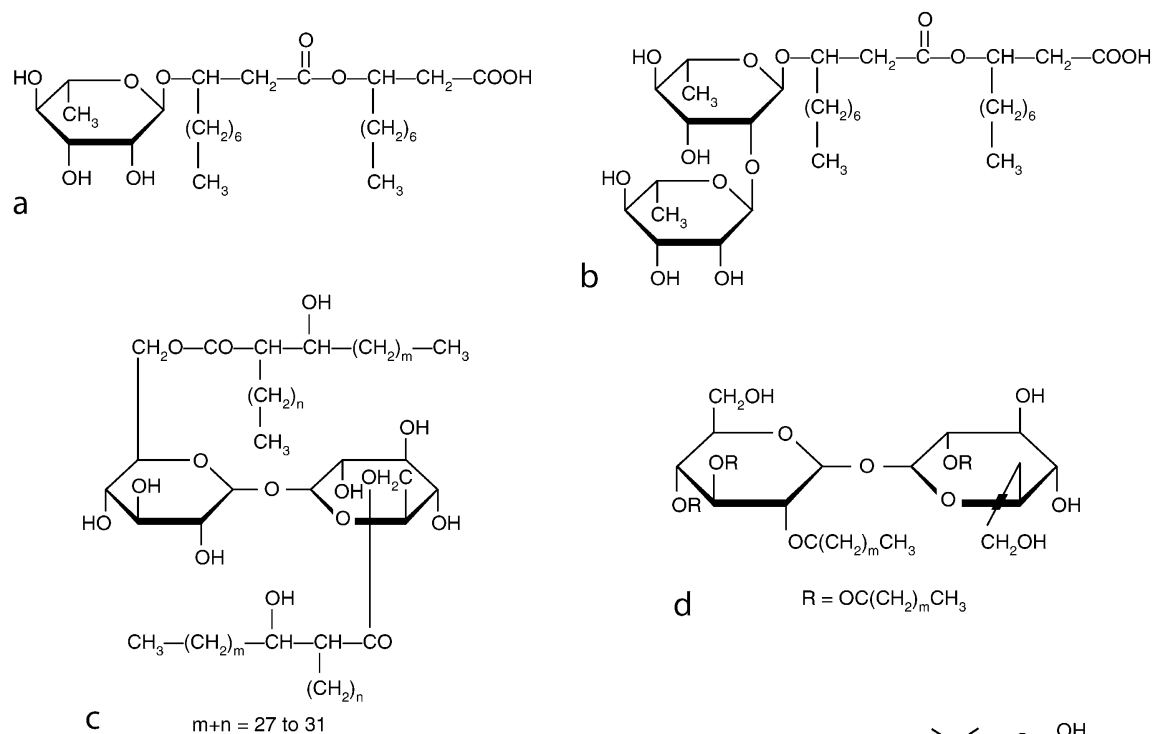

d

$$
\mathrm{R}=\mathrm{OC}\left(\mathrm{CH}_{2}\right)_{\mathrm{m}} \mathrm{CH}_{3}
$$
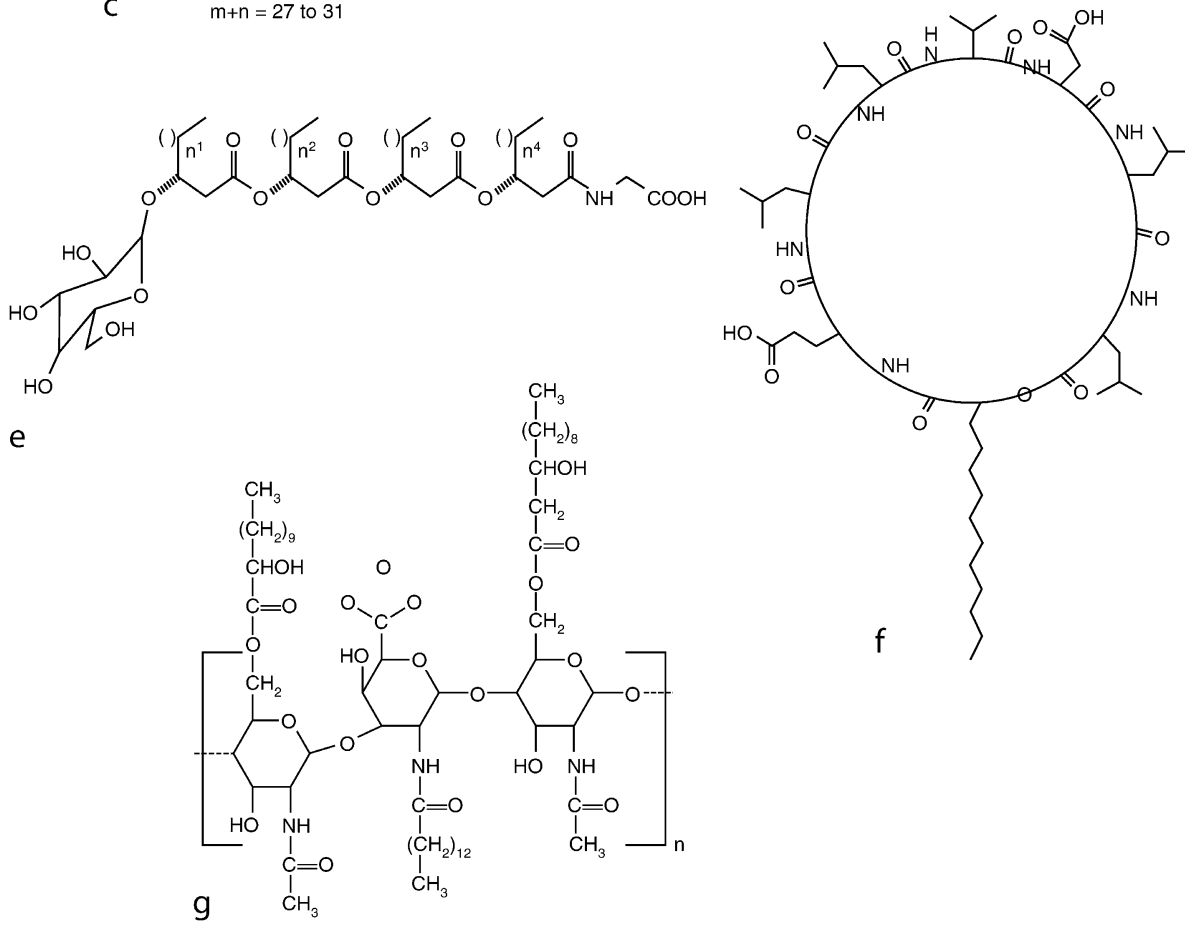

Figure 1

Structures of selected biosurfactants and bioemulsifiers from the most representative hydrocarbon-degrading microorganisms. L-rhamnosyl-3-hydroxydecanoyl-3-hydroxydecanoate (mono-rhamnolipid- $\mathrm{C}_{10}-\mathrm{C}_{10}$ ) (a) and L-rhamnosyl-L-rhamnosyl-3-hydroxydecanoyl-3hydroxydecanoate (di-rhamnolipid- $\mathrm{C}_{10}-\mathrm{C}_{10}$ ) (b) from Pseudomonas aeruginosa; trehalosedicorynomycolate (c) and trehalose-tetraester (d) from Rhodococcus sp.; glucolipid from Alcanivorax borkumensis (e); surfactin from Bacillus sp. (f); emulsan from Acinetobacter RAG-1 (g). 
low levels on both water-soluble and hydrophobic substrates with the concentration increasing during the late exponential-early stationary phase as a consequence of the higher cell density. The expression of the rhlAB operon and rhlC gene encoding the two rhamnosyltransferases responsible for the biosynthesis is under the control of the rhlR/rhlI genes, whose regulation is integrated into the quorum-sensing system (Soberon-Chavez et al., 2005).

Most of our knowledge of rhamnolipid biosurfactants derives from investigations carried out in shaken-liquid cultures supplemented with hydrophobic compounds. In such conditions rhamnolipids are released into the medium as monomers that aggregate into micelles and larger vesicles when the concentration reaches and exceeds a critical level known as the critical micelle concentration (CMC). Hydrocarbons become incorporated within the hydrophobic core of micelles and this effectively enhances their dispersion into the aqueous phase and hence their bioavailability for uptake by cells. This process has been largely studied with alkanes as model substrates and is referred to as "micelle solubilization" or "pseudosolubilization" (『 Figs. 2 and ( 3) (Zhang and Miller, 1992).

In addition rhamnolipids act on the cell outer membrane modifying the hydrophilic nature by inducing the release of lipopolysaccharide components with a subsequent increase of surface hydrophobicity. This enhances the affinity of cells for the hydrophobic substrate facilitating access to the finely dispersed oil droplets (Al-Tahhan et al., 2000).

This same mode of action also seems to be involved in the uptake of solid and non-aqueous phase liquid (NAPL) polycyclic aromatic hydrocarbons. Small amounts of surface-exposed biosurfactants and polymeric substances available when cell numbers are low allow initial growth at the interface between water and oil and is essential to start the mass transfer of the substrate into the bulk aqueous phase and provide an initial carbon input that further supports the development of a bigger competent bacterial community (García-Junco et al., 2001).

In solid phases such as soil, sediment, sand or organic matter, where the hydrophobic substrates can be present as solid particles or liquid film adsorbed onto the matrix or sequestered in pores and the bacteria are heterogeneously distributed, the production of biosurfactants first increases the substrate accessibility and reduces its spatial separation from the degrading cells. Rhamnolipids are believed to aggregate at the solid interface forming single mono-layers known as hemi-micelles capable of desorbing the hydrophobic substrates thus increasing their bioavailability in the aqueous phase (Volkering et al., 1998). However,
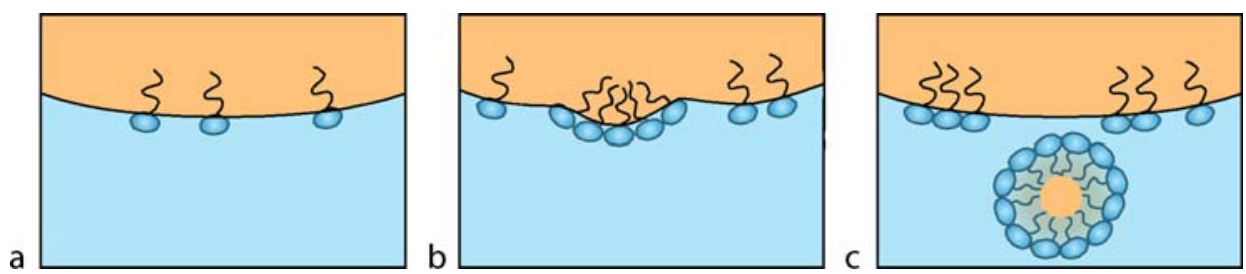

Figure 2

Mechanism of hydrocarbon solubilization within biosurfactant micelles. At low concentration, biosurfactants occur as monomers at the interface between the aqueous and hydrocarbon phases (a). When the concentration increases and the space available decreases, biosurfactants tend to arrange into aggregates (b) up to a point called the "critical micelle concentration" at which micelles are formed trapping the hydrocarbons into their hydrophobic core (c). Once dispersed, hydrocarbons become more available to uptake by the cells. 


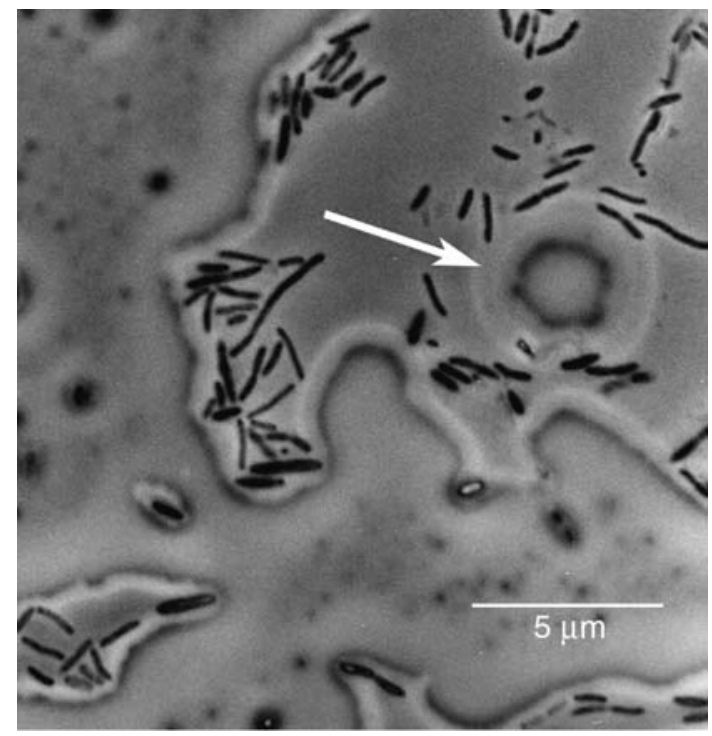

Figure 3

Photomicrograph of a mixed population of bacteria growing in the presence of hydrocarbons. Cells tend to occur at the interface between the aqueous and hydrophobic phases and a micelle (see arrow) can be also observed.

experimental conditions may present a quite different scenario. In soil microcosms where hydrocarbons are well mixed and the bacteria homogenously distributed over the available surface, the distance between substrate and cells is artificially reduced making direct contact the preferred uptake mode. Although the expression of rhamnolipids is constitutive, their contribution to hydrocarbon degradation is probably marginal (Holden et al., 2002).

\section{Surface-Active Lipids of Rhodococcus and Mycolate-Containing Microorganisms}

Rhodococcus is one of the most active hydrocarbon-degrading bacterial genera due to a broad set of potent enzymes, oxygenases in particular, and robust cellular physiology. Their ability to produce biosurfactants is one of the numerous adaptations induced by the presence of hydrocarbons.

Uptake of alkanes occurs via direct access to large oil drops by the cells with biosurfactants mediating the interaction. This implies that biosurfactants are synthesized in a growthassociated manner and that most of them remain wall-bound conferring the cell surface with that essential hydrophobicity through which the contact with the substrate can take place. Other components of the cell wall such as glycolipids, mycolic and fatty acids also contribute to the remarkably hydrophobic nature of Rhodococcus and the CMN group (Corynebacterium, Mycobacterium and Nocardia). An additional effect is that wetting of the cell surface is hampered and this further supports the access to hydrocarbons. Only a small portion of biosurfactants, estimated to be approximately $10 \%$, are in fact released into the culture medium to help the preliminary emulsification of the oil (Lang and Philp, 1998). 
Growth and metabolic activities of Rhodococcus therefore occur at the hydrocarbon-water interface giving liquid cultures a typical appearance with a clear aqueous phase and a top layer rich in cells and flocculating material adhering to the hydrocarbons.

The chemical features of Rhodococcus biosurfactants reflect their physiological role. A large number of different glycolipids can be produced but trehalose lipids composed of trehalose as the sugar moiety linked to fatty acids represent the predominant type. The fatty acid portion is highly variable among the producing strains, with very long chain length from $\mathrm{C}_{20}$ to $\mathrm{C}_{90}$ and structures complicated by numerous branches and substitutions ( $>$ Fig. 1c). Trehalose lipids are therefore well suited to remain anchored to the cell wall along with the other components, whereas self-assembly in cell-free aggregates would not be favored. In addition, it is worth mentioning that the hydrophile-lipophile balance (HLB) of the biosurfactant molecule is significantly affected by the number of possible fatty acid chains and it is likely that the cells modulate the overall properties of their surface shifting from hydrophilic to hydrophobic and vice versa to interact with different substrates (Neu, 1996).

Another interesting point is that, in addition to the more frequent non-ionic form biosurfactant (e.g., trehalose mycolates and derivatives), trehalose lipids can be synthesized as anionic tetraesters (Rapp and Gabriel-Jürgens, 2003) (\$ Fig. 1d). These latter products are preferentially secreted and are believed to contribute to a greater extent in the emulsification process of hydrophobic compounds.

The role of trehalose lipids and glycolipids in Rhodococcus and related genera is however far from being completely elucidated as several issues remain unresolved. It is not clear for example whether they are involved in the uptake of aromatic and polycyclic aromatic hydrocarbons. Biofilm formation onto a solid hydrophobic substrate is a recognized situation for members of the Mycobacterium genus and it is expected that biosurfactants may be involved in the architecture and functionality of such biofilms.

It is also worth mentioning that it has been hypothesized that members of Gordonia genus are capable of switching the mode of access to hydrocarbons at different stages of the growth. A change from an initial direct contact to large oil droplets to emulsified/dispersed droplets seems to be triggered by the differently timed production of both cell-bound biosurfactants and extracellular emulsifying agents along with an active modification of cell surface hydrophobicity/hydrophilicity (Franzetti et al., 2008).

\section{$5 \quad$ Glycolipids of Alcanivorax in Marine Environments}

Spills of oil and hydrocarbons in marine environments stimulate the indigenous community of obligate hydrocarbonoclastic bacteria $(\mathrm{OHCB})$ to flourish becoming the majority of the total microbial population (Yakimov et al., 2007). Very few genera of highly specialized hydrocarbon degraders form these populations with Alcanivorax borkumensis the most dominant.

This bacterium is known for its ability to grow metabolizing only alkanes and producing glycolipidic biosurfactants (Yakimov et al., 1998). The major glycolipid synthesized comprises a glucose sugar linked to a tetrameric chain of fatty acids of $\mathrm{C}_{6}-\mathrm{C}_{10}$ length and interestingly exists both in cell-associated and secreted forms. The former is esterified at the $\mathrm{N}^{\prime}$-terminus with a unique glycine residue and it is believed to be the precursor of the released glycine-free form (Abraham et al., 1998) (\$ Fig. 1e). Therefore, the strategy of A. borkumensis to get access to hydrocarbon involves both the solubilization of the substrate within micelles and the subsequent direct uptake of the finely dispersed droplets. 
The genetic organization of the glycolipid biosynthesis is still unidentified but the recent sequencing of A. borkumensis SK2 genome has provided interesting insights into interspecies similarity. For example, the protein encoded by gene ABO_1783 is a glycosyltransferase showing homology with the rhamnosyltransferase 1 (RhlB) of Pseudomonas aeruginosa which catalyzes the formation of monorhamnolipids. In addition, gene ABO_0822 encodes a putative OprF/OmpA-like protein that represents the active component of the bioemulsifier alasan of Acinetobacter radioresistens KA53 (Schneiker et al., 2006).

\section{6} The Lipopeptide Biosurfactants

The second major group of microbial biosurfactants is represented by the lipopeptides that are synthesized by a wide range of genera including fluorescent pseudomonads and bacilli. Due to their exceptional ability to interact with the cell membrane, lipopeptides are well known antimicrobials although in the presence of hydrophobic compounds they act as powerful surfactants displaying a broad range of activities.

Bacillus lipopeptides in particular are the best known. Their genetic organization comprises a large operon ( $r f A)$ and a biosynthetic system led by non ribosomal peptide synthetases (NRPSs), which provides some explanation for the heterogeneity and variability of these compounds in terms of molecular structures and subsequent activities. They are essentially simple molecules composed of a cyclic peptide backbone linked to a fatty acid tail. Numerous variants and isoforms however exist with regards to the number (7-10), type and sequence of the amino acid residues, the nature of the peptide cyclization and the type, length $\left(\mathrm{C}_{13}-\mathrm{C}_{18}\right)$ and branching of the chain (Ongena and Jacques, 2007) (\$ Fig. 1f). Minor changes at the level of even a single amino acid can result in a significant effect on the overall behavior of the molecule due to changes in the hydrophile-lipophile balance.

Being secondary metabolites, lipopeptides are also produced as mixtures of different congeners whose composition is probably related to specific nutritional and environmental requirements of the cells. For example two strains of $B$. subtilis isolated from different environments and able to grow using different substrates, i.e., starch and hydrocarbons, were found to produce different lipopeptides, iturin and surfactin respectively. These strains were spontaneously incapable of swapping carbon source but when the starch-utilizing strain was supplemented with the surfactin lipopeptide produced by the hydrocarbon-degrading strain, it gained the ability to utilize hexadecane and vice versa (Murkherjee and Das, 2005).

Moreover, bacteria adapted to thrive in extreme environments such as B. licheniformis and B. mojavensis indigenous to oil reservoirs produce lichenysin lipopeptide under conditions unusual for mesophilic strains i.e., low oxygen tension, high temperature (up to $45^{\circ} \mathrm{C}$ ) and high salinity (up to 8\%) (Javaheri et al., 1985; Yakimov et al., 1995). Lichenysin is also known for being particularly effective in reducing interfacial tension, which is of crucial importance to free the oil from the rock pores both mobilizing it and making it available to the bacteria.

Hydrocarbon-degrading bacilli produce lipopeptides and secrete them into the medium where they assemble to form micelles that act to solubilize and emulsify the substrate. Besides being excellent foaming agents, these biosurfactants are in general very active at the interface level due to the ultra low interfacial tensions (IFT) of $0.01 \mathrm{mN} / \mathrm{m}$ that they are able to generate. In addition, lipopeptides may modulate the bacterial hydrophobicity. It has been suggested that they may adsorb onto the cell surface alternately exposing the cyclic peptide (hydrophilic) 
or the fatty acid tail end (hydrophobic) thus altering the surface properties in response to specific needs (Ahimou et al., 2000).

It seems clear therefore that the contribution of lipopeptides is not merely limited to hydrocarbon access but may more broadly confer an evolutionary advantage to the producing bacteria in response to prevailing environmental conditions and substrate availability.

\section{$7 \quad$ High Molecular Mass Bioemulsifiers}

These are structurally complicated biopolymers, polysaccharides, proteins, lipopolysaccharides, lipoproteins and mixtures of these components, and are amphiphatic in nature, similar to the low molecular mass glycolipids and lipopeptides. Owing to the high number of reactive groups exposed across these molecules, they can bind tightly to hydrocarbons and oil forming a barrier that prevents drop coalescence. Thus, they show an outstanding capability to stabilize emulsions as highlighted by the fact that they are often referred to as bioemulsifiers (Ron and Rosenberg, 2002). Numerous bioemulsifiers have been described so far but a comprehensive body of knowledge has been produced on Acinetobacter emulsifiers, which has been mainly carried out by Rosenberg's group (Rosenberg and Ron, 1997).

Oil-degrading strains of Acinetobacter produce a range of different biosurfactants, among which Acinetobacter RAG-1 emulsan was one of the first described. It is composed of several hydrophobic fatty acid chains branching from an anionic heteropolysaccharidic backbone thus resembling a comb-like structure ( $($ Fig. $1 g)$. The surface activities are expressed by the fatty acid components that act as multiple sites anchoring the oil phase. In pure form, emulsan shows emulsifying activity at low concentrations (0.01-0.001\%) and considerable substrate specificity.

Its natural role is to facilitate interaction and substrate access by the bacterium. During the growth of Acinetobacter RAG-1 in the presence of crude oil, emulsan is cell-associated and forms a minicapsule that allows the bacterium to attach to oil drops. RAG-1 metabolizes only long chain alkanes until their complete depletion. Once starving, the cells regulate their detachment from the exhausted oil droplets by releasing the emulsan capsule. This has two major consequences. First, bacterial cells are enabled to move to access fresh substrate while the released emulsan capsule labels the utilized droplets as unavailable for binding by the hydrophilic outer surface of Acinetobacter, yet available to other oil-degrading microorganisms with affinity for the remaining aromatic and paraffinic hydrocarbons. Second, it is the released form of emulsan that displays emulsifying activity and this further enhances the substrate bioavailability. The synthesis of emulsan however is not a limited response to hydrophobic compounds and soluble carbon compounds such as ethanol allow higher product yields and preferentially lead to an increase in the secreted form (Choi et al., 1996).

Alasan, a bioemulsifier produced by Acinetobacter radioresistens KA53, significantly differs from RAG-1 and other biopolymers in many respects. It is a complex formed by anionic alanine-containing polysaccharides and proteins with a molecular mass of approximately $1 \mathrm{MDa}$ (Navon-Venezia et al., 1995). One interesting feature is that the surface activity resides in the protein components. AlnA in particular is a $45 \mathrm{kDa}$ protein showing a $\beta$-barrel transmembrane structure with four highly hydrophobic regions folded over in loops that are mainly responsible for the emulsification and solubilization activity. AlnA displays homology with the outer membrane OmpA proteins of Gram-negative bacteria and it has been suggested it might constitute the OmpA of A. radioresistens KA53 strain. However, its existence as both 
cell-bound and secreted protein opens a new perspective on the physiological role of AlnAOmpA and highlights the importance of biological emulsification in the utilization of hydrocarbons as carbon and energy sources (Walzer et al., 2006).

Pure AlnA effectively emulsifies a wide range of hydrophobic compounds, long chain alkanes, aromatics, PAHs, paraffins and crude oil. The mechanism of PAH solubilization has been elucidated and it is specific among the various strategies adopted by degrading bacteria. One or few PAH molecules initially bind an AlnA monomer followed by more AlnA monomers that assemble to form a 5-8 unit oligomer, which in turn binds additional PAH molecules. In this way, PAH apparent solubility is enhanced up to 20 -fold and hence the biodegradation rates significantly increase (Toren et al., 2002).

Less is known about polymeric biosurfactants synthesized by other microorganisms. Sphingans for example are produced by sphingomonads and constitute a family of exopolysaccharides (EPS) structurally related by the same tetrasaccharidic backbone (X-glucoseglucuronic acid-X, with $\mathrm{X}$ being rhamnose or mannose) to which distinct side chains are attached. Sphingans are able to adsorb to PAHs, although there is no clear evidence that this strategy really increases the apparent substrate solubility and therefore the mass transfer to the cells. Sphingomonas strains are widely distributed in soil and one hypothesis is that in such heterogeneous environment PAHs may be accumulated by sphingans in biofilms and then accessed by the cells (Johnsen and Karlson, 2004).

Halomonas eurihalina is another bacterium able to synthesize EPS with emulsifying activity in the presence of hydrocarbons though this is not necessarily a direct response. Bioemulsifier chemical composition varies according to the substrate: EPS produced on hydrocarbons have less carbohydrate and protein components but are richer in uronic acids than EPS produced on glucose. Uronic acids in particular may be involved in the detoxification of hydrocarbons thus representing a form of adaptation. Moreover substratedependent changes in the structure confer on the polymer a specific and higher activity on the same substrate. One interesting aspect of Halomonas bioemulsifiers is that, like other biosurfactants, they are able to stimulate the growth of other hydrocarbon-degrading bacteria such as Bacillus, Pseudomonas, Micrococcus and Arthrobacter (Calvo et al., 2002; MartínezCheca et al., 2002).

\section{$8 \quad$ Research Needs and Conclusions}

The investigations collected over the past few decades have given evidence of the central role played by biosurfactants in hydrocarbon-degrading microorganisms but more work is clearly required to fulfill still numerous gaps. A major obstacle to progress is that our present understanding of biosurfactant production remains limited by inadequate and inconsistent screening methodology. Most of the existing assays are indirect methods based on the evaluation of physical and chemical properties or surface activities of biosurfactants and therefore require a preliminary cell cultivation step. This is, however, influenced by several factors such as carbon substrate and source and concentration of microelements and nitrogen in particular, which may produce unrepresentative results. Molecular approaches to screening for biosurfactant producers remain in their infancy, hampered by the fact that the biosynthetic pathways and genes are highly conserved at the level of species and that the current body of knowledge is restricted to very few organisms. While genetic strategies need to be strengthened and the gene database widened, new research directions towards novel or poorly explored bacteria should 
also be encouraged. Important insights into the diversity and function of biosurfactants are therefore expected to be achieved on the basis of advances in the genomic and proteomic areas of microbiology in the near future.

\section{References}

Abraham W-R, Meyer H, Yakimov M (1998) Novel glycine containing glucolipids from the alkane using bacterium Alcanivorax borkumensis. Biochim Biophys Acta 1393: 57-62.

Ahimou F, Jacques P, Deleu M (2000) Surfactin and iturin A effects on Bacillus subtilis surface hydrophobicity. Enzyme Microb Technol 27: 749-754.

Al-Tahhan RA, Sandrin TR, Bodour AA, Maier RM (2000) Rhamnolipid-induced removal of lipopolysaccharide from Pseudomonas aeruginosa: effect on cell surface properties and interaction with hydrophobic substrates. Appl Environ Microbiol 66: 3262-3268.

Banat IM, Makkar SR, Cameotra SS (2000) Potential commercial application of microbial surfactants. Appl Microbiol Biotechnol 53: 495-508.

Bodour AA, Drees KP, Maier RM (2003) Distribution of biosurfactant-producing bacteria in undisturbed and contaminated arid southwestern soils. Appl Environ Microbiol 69: 3280-3287.

Calvo C, Martínez-Checa F, Toledo FL, Porcel J, Quesada E (2002) Characteristics of bioemulsifiers synthesised in crude oil media by Halomonas eurihalina and their effectiveness in the isolation of bacteria able to grow in the presence of hydrocarbons. Appl Microbiol Biotechnol 60: 347-351.

Choi JW, Choi HG, Lee WH (1996) Effects of ethanol and phosphate on emulsan production by Acinetobacter calcoaceticus RAG-1. J Biotechnol 45: 217-225.

Desai JD, Banat IM (1997) Microbial production of surfactants and their commercial potential. Microbiol Mol Biol Rev 61: 47-64.

Franzetti A, Bestetti G, Caredda P, La Colla P, Tamburini E (2008) Surface-active compounds and their role in the access to hydrocarbons in Gordonia strains. FEMS Microbiol Ecol 63: 283-248.

García-Junco M, De Olmedo E, Ortega-Calvo J-J (2001) Bioavailability of solid and non-aqueous phase liquid (NAPL)-dissolved phenanthrene to the biosurfactant-producing bacterium Pseudomonas aeruginosa 19SJ. Environ Microbiol 3: 561-569.

Gunther NW IV, Nuñez A, Fett W, Solaiman DK (2005) Production of rhamnolipids by Pseudomonas chlororaphis, a non-pathogenic bacterium. Appl Environ Microbiol 71: 2288-2293.

Holden PA, LaMontagne MG, Bruce AK, Miller WG, Lindow SE (2002) Assessing the role of Pseudomonas aeruginosa surface-active gene expression in hexadecane biodegradation in sand. Appl Environ Microbiol 68: 2509-2518.

Hommel RK (1990) Formation and physiological role of biosurfactants produced by hydrocarbon-utilizing microorganisms. Biosurfactants in hydrocarbon utilization. Biodegradation 1: 107-119.

Javaheri M, Jenneman GE, McInerney MJ, Knapp RM (1985) Anaerobic production of a biosurfactant by Bacillus licheniformis JF-2. Appl Environ Microbiol 50: 698-700.

Johnsen AR, Karlson U (2004) Evaluation of bacterial strategies to promote the bioavailability of polycyclic aromatic hydrocarbons. Appl Microbiol Biotechnol 63: 452-459.

Johnsen AR, Wick LY, Harms H (2005) Principles of microbial PAH-degradation in soil. Environ Poll 133: 71-84.

Lang S, Philp JC (1998) Surface-active lipids in rhodococci. Antonie van Leeuwenhoek 74: 59-70.

Martínez-Checa F, Toledo FL, Vilchez R, Quesada E, Calvo C (2002) Yield production, chemical composition, and functional properties of emulsifier H28 synthesized by Halomonas eurihalina strain H-28 in media containing various hydrocarbons. Appl Microbiol Biotechnol 58: 358-363.

Mukherjee AK, Das K (2005) Correlation between diverse cyclic lipopeptides production and regulation of growth and substrate utilization by Bacillus subtilis strains in a particular habitat. FEMS Microbiol Ecol 54: 479-489.

Navon-Venezia S, Zosim Z, Gottlieb A, Legmann R, Carmeli S, Ron EZ, Rosenberg E (1995) Alasan, a new bioemulsifier from Acinetobacter radioresistens. Appl Environ Microbiol 61: 3240-3244.

Neu TR (1996) Significance of bacterial surface-active compounds in interaction of bacteria with interfaces. Microb Rev 60: 151-166.

Ongena M, Jacques P (2007) Bacillus lipopeptides: versatile weapons for plant disease biocontrol. Trends Microbiol 16: 115-125.

Rahman KSM, Thahira-Rahman J, Lakshmanaperumalsamy P, Banat IM (2002) Occurrence of crude oil degrading bacteria in gasoline and diesel station soils. J Basic Microbiol 42: 286-293.

Rapp P, Gabriel-Jürgens LHE (2003) Degradation of alkanes and highly chlorinated benzenes, and 
production of biosurfactants, by a psychrophilic Rhodococcus sp. and genetic characterization of its chlorobenzene dioxygenase. Microbiology 149: 2879-2890.

Ron EZ, Rosenberg E (2002) Biosurfactants and oil bioremediation. Curr Opin Biotechnol 13: 249-252.

Rosenberg E, Ron EZ (1997) Bioemulsans: microbial polymeric emulsifiers. Curr Opin Biotechnol 8: 313-316.

Schneiker S, Martins dos Santos VAP, Bartels D, et al. (2006) Genome sequence of the ubiquitous hydrocarbon-degrading marine bacterium Alcanivorax borkumensis. Nat Biotechnol 24: 997-1004.

Soberon-Chevez G, Lépine F, Déziel E (2005) Production of rhamnolipids by Pseudomonas aeruginosa. Appl Microbiol Biotechnol 68: 718-725.

Toren A, Ron EZ, Bekerman R, Rosenberg E (2002) Solubilization of polyaromatic hydrocarbons by recombinant bioemulsifier AlnA. Appl Microbiol Biotechnol 59: 580-584.

Van Hamme JD, Singh A, Ward OP (2006) Surfactants in microbiology and biotechnology: Part 1. Physiological aspects. Biotechnol Adv 24: 604-620.
Volkering F, Breure AM, Rulkens WH (1998) Microbiological aspects of surfactant use for biological soil remediation. Biodegradation 8: 401-417.

Walzer G, Rosenberg E, Ron EZ (2006) The Acinetobacter outer membrane protein A (OmpA) is a secreted emulsifier. Environ Microbiol 8: 1026-1032.

Yakimov MM, Golyshin PN, Lang S, Moore ERB, Abraham W-R, Lünsdorf H, Timmis KN (1998) Alcanivorax borkumensis gen. nov., sp. nov., a new, hydrocarbon-degrading and surfactant-producing marine bacterium. Int J Syst Bacteriol 48: 339-348.

Yakimov MM, Timmis KN, Golyshin PN (2007) Obligate oil-degrading marine bacteria. Curr Opin Biotechnol 18: 257-266.

Yakimov MM, Timmis KN, Wray V, Fredrickson HL (1995) Characterization of a new lipopeptide surfactant produced by thermotolerant and halotolerant subsurface Bacillus licheniformis BAS50. Appl Environ Microbiol 61: 1706-1713.

Zhang Y, Miller RM (1992) Enhanced octadecane dispersion and biodegradation by a Pseudomonas rhamnolipid surfactant (biosurfactant). Appl Environ Microbiol 58: 3276-3282. 